\title{
Reengineering India: Work, Capital, and Class in an Offshore Economy by Carol Upadhya
}

\section{Oxford University Press, New Delhi, 2016, pp xiii + 383 pp, ₹995}

\section{Lars Olav Aaberg ${ }^{1}$}

Published online: 22 April 2019

(C) Indian Society of Labour Economics 2019

In Carol Upadhya's Reengineering India: Work, Capital, and Class in an Offshore Economy, we are presented with an anthropological investigation into the meaning of labour in the information technologies (IT) industry. The monograph is based on fieldwork conducted over a period of 18 months based mostly in Bengaluru, India, but also includes ethnographic data and analysis of IT work and workers in the Netherlands and Germany. The book provides an analysis of how subjectivities of those working in IT are shaped by an industry considered the hallmark of a postliberalization economy and one that offers hope and social mobility for India's youth from various social locations. While the IT industry in India is mostly associated with social mobility that promises to unshackle economically deprived segments from class- and caste-based barriers, Upadhya presents a detailed account of how the IT industry is a site wherein inequality is reproduced rather than subverted for many of its actors.

The book is divided into six chapters together with the introduction and conclusion. In chapters one and two, the author delineates the histories of how the IT industry came into being in India and how it creates its workforce. The IT industry has wielded vast moral capital not least through its own comparisons to the Indian state, claiming superiority on the grounds that it is more democratic and transparent. The author begins to take this claim to task, first by analysing how different IT firms recruit candidates. Recruitment often begins before students pass out of their bachelor's degrees, as companies go to university campuses, interview students and offer them tentative employment contracts. Beyond technical skills, students face two means of evaluation: their grades and their cultural 'fit'. Upadhya argues that the recruitment process tends to draw from the relatively privileged within India's higher education due to this highly subjective element of the recruitment process. The focus on grades tend to privilege students who were not admitted through

Lars Olav Aaberg

lars.olav.aaberg@gmail.com

1 Centre for Gender Studies, School of Oriental and African Studies (SOAS), London, UK 
caste-based quotas, which provide lower grade thresholds for admission, while cultural 'fit' favours those who have had greater access to cultural capital in terms of English-language skills and exposure to urban culture, which IT firms see as necessary skills for interacting with foreign clients.

In chapter three and four, Upadhya brings us into the world of management controls and how value is extracted from IT labour through technologies of surveillance. In the 'software factory', we find that the management of time and mental labour are paramount as the abstraction of IT labour comes from engineers' tacit knowledge; however, we see that tight management of labourers takes on new forms under a regime of 'soft capitalism'. 'Soft capitalism' employs 'new age' management techniques, which seek to cultivate labourers as entrepreneurial subjects whose ethics and desires fall in line with the overall aims of corporate value creation. These techniques diverge from the brute exploitation of labour that one expects from older forms of capital. The IT workplace is refashioned into the primary site through which labour develops a sense of self and, for Bangalore's highly dislocated IT cohort, is even the main place where employees form their social networks. The author holds these novel forms of labour management in tension with what might at first blush seem to be contradictory forms of surveillance and control from above directed at the minute experiences of work. Throughout these chapters, the author provides ethnographic material showcasing how employees try to negotiate, resist or otherwise manoeuvre within multiple regimes of control present in the 'modern' workplace, one that is better described as a coagulation of 'soft capitalism' and older vestiges of value extraction, variously disparaged by the IT industry and its leaders as quintessentially Indian, traditional and non-urban.

In chapters five and six, we are given more detail of how the neoliberal self is fashioned through other skills programmes not directly related to one's job but are presented as necessary for success in a 'global' industry. 'Soft' and 'life' skills training, and courses in European etiquette, are examples of how companies attempt to goad Indian labourers into conceptions of the neoliberal self through a reorientation of values, promoting an ethics of self-management, adaptability and flexibility which seek to manage and acclimate to the uncomfortable conditions of labouring rather than 'trying to change the conditions that produce stress' (241.) Upadhya points out that one's success in these cultural projects has more to do with one's access to various forms of capital outside the workplace rather than one's ability to produce capital from inside the software factory (210-211.) Upadhya then maps out the tripartite fractioning of the so-called 'new middle class' onto the categories of 'transnational' and 'cosmopolitan', which roughly correlate with the middle class's 'middle' and 'upper' fractions, respectively. This division is most salient when Indian IT labourers must interact with foreign clients or spend prolonged periods overseas. The 'transnational' midsection of the middle class takes centre stage in the analysis, as she details her informants' claims to middle class status through their emphasis on religious and conservative mores reflected in expressed tropes of 'family values', traditionally gendered divisions of labour and consumption practices. While the 'cosmopolitan' or upper-middle fraction is briefly detailed through ethnographic vignettes, the lower-middle class is only alluded to and little ethnographic data are provided. Upadhya then concludes her work poignantly: 'The more capital 
encounters difference, the more it endeavours to domesticate it through the management of culture' (339).

Though gender is given mention throughout the book, it is primarily in occasional references to disparities in benefits for women or how class structures women's access to formal employment. Aside from scattered instances of explicit analysis in subsections dedicated to gender, gender is mostly associated with women and the concept itself is not scrutinized. Indeed, IT's oft disparaged 'bachelor' culture and the cult personalities who founded firms like Wipro and Infosys are both mentioned in text and with more scrutiny, they could teach us something about men and changing processes of masculinity in contemporary India. In similar fashion, the author remains cautious about subjecting theories of the self to the same scrutiny she gives other facets of the IT story. Upadhya's negative appraisal of soft skills training proves indicative of this: 'Although these techniques are supposed to "empower" employees, they create yet another dimension of power by requiring them to acknowledge a lack in themselves that needs to be corrected' (224, emphasis added). On the razor's edge of a classic psychoanalytic assessment, the author gestures here and elsewhere towards important theories of the self though refrains from fully engaging in their messy details. This is important in light of how central the refashioning of the self is to corporate culture. Nevertheless, one of the book's chief strengths is its ethnographic detail and sharp analysis, which opens the text up for the extrapolation of the aforementioned subjects. Reengineering India's detailed scrutiny of the many facets of life in the IT industry proves an invaluable resource for those interested in IT specifically but also those interested in globalized workplaces, post-liberalization India and theories of cultural capital.

Publisher's Note Springer Nature remains neutral with regard to jurisdictional claims in published maps and institutional affiliations. 